\title{
A new species of Themus (Themus) Motschulsky from Yunnan, China and a redescription of T. (T.) testaceicollis Wittmer, 1983 (Coleoptera, Cantharidae)
}

\author{
Junyan Su', Limei Li', Yuxia Yang', Xingke Yang ${ }^{2}$
}

I The Key Laboratory of Zoological Systematics and Application, College of Life Sciences, Hebei University, Baoding 071002, Hebei Province, China 2 Key Laboratory of Zoological Systematics and Evolution, Institute of Zoology, Chinese Academy of Sciences, Beijing 100101, China

Corresponding author: Yuxia Yang (yxyang@hbu.edu.cn)

Academic editor: L. Penev | Received 17 April 2015 | Accepted 28 August 2015 | Published 5 October 2015

http://zoobank.org/F259E0E2-CA75-4197-8B3F-A0191734EC74

Citation: Su J, Li L, Yang Y, Yang X (2015) A new species of Themus (Themus) Motschulsky from Yunnan, China and a redescription of T. (T.) testaceicollis Wittmer, 1983 (Coleoptera, Cantharidae). ZooKeys 525: 107-116. doi: 10.3897/ zookeys.525.6021

\begin{abstract}
A new species is described, Themus (Themus) dimorphus sp. n. from Yunnan, China. Themus (Themus) testaceicollis Wittmer, 1983 is redescribed and compared with the new species. The two species are illustrated with habitus and genitalia of both sexes and abdominal sternites VIII of female.
\end{abstract}

\section{Keywords}

Taxonomy, Cantharidae, Themus, new species, China

\section{Introduction}

The genus Themus Motschulsky, 1858 was divided into four subgenera (Wittmer 1973, 1997), whose diagnoses were redefined by Švihla (2008). The nominotypical subgenus includes more than 100 species widely distributed in the Oriental and eastern Palaearctic regions (Švihla 2008). In China, approximately 50 species of this subgenus are known, and most species were described or revised by Wittmer (1983).

Copyright Junyan Su et al. This is an open access article distributed under the terms of the Creative Commons Attribution License (CC BY 4.0), which permits unrestricted use, distribution, and reproduction in any medium, provided the original author and source are credited. 
In recent study, a new species was discovered from Yunnan, China and is described here under the name of Themus (Themus) dimorphus sp. n. It is similar to T. (T.) testaceicollis Wittmer, 1983, which is redescribed in the present study to make comparisons with the new species.

\section{Material and methods}

The types or other specimens are deposited in the following collections:

IZAS Institute of Zoology, Chinese Academy of Sciences, Beijing, China;

MHBU Museum of Hebei University, Baoding, China;

MNHN Muséum national d'Histoire naturelle, Paris, France;

NHMB Naturhistorisches Museum Basel, Switzerland.

The studied method and description format follow that of Yang et al. (2014). Morphological terminology of female genitalia follows that of Brancucci (1980) and abbreviations in the figures are listed as follows: ag accessory gland; co coxite; di diverticulum; tg9 abdominal tergite IX; sp spermatheca; ov median oviduct; va vagina; sr sclerotized bracket or ridge.

\section{Taxonomy}

\section{Themus (Themus) dimorphus Y. Yang \& X. Yang, sp. n.}

Figs 1A-B, 2A-C, G, 3

Type material. Holotype, male (MHBU): CHINA: Yunnan, Yiliang, Xiaocaoba, 25.VIII.2013, leg. Xun Bian \& Guang-Lin Xie; Paratypes: 2 males (MHBU): same data to the holotype; 2 females (MHBU): same locality and collectors, 24.VIII.2013.

Description. Male (Fig. 1A). Head metallic dark blue and weakly shining, lateral parts of clypeus yellow, mouthparts yellow, maxillary and labial palpi and apices of mandibles dark brown; prothorax yellow, pronotum with a moderately large, irregular black marking in center of disc, antennae black, antennomeres I-III yellow on ventral sides, scutellum black, elytra metallic green and weakly shining, legs and meso- and metasterna metallic dark blue and weakly shining, abdomen yellow, slightly darkened on both sides of ventrites $\mathrm{I}-\mathrm{V}$. Body densely covered with decumbent brown pubescence, mixed with slightly long semierect pubescence on elytra and a few long hairs along anterior margin of clypeus.

Head rounded, densely and finely punctate, surface lustrous; eyes slightly protruding, breadth across eyes slightly wider than anterior margin of pronotum; terminal maxillary palpomeres widest nearly in middle, arcuate and sharp at apical parts of inner margins, rounded at apices; antennae extending to basal two-fifth length of elytra, antennomeres II approximately twice as long as wide at apices, III-X slightly obliquely widened apicad, III 



Figure I. Habitus, dorsal view (A, C male B, D female): A-B Themus (Themus) dimorphus sp. n. C-D T. (T.) testaceicollis Wittmer, 1983. Scale bars $=2.0 \mathrm{~mm}$. 




A

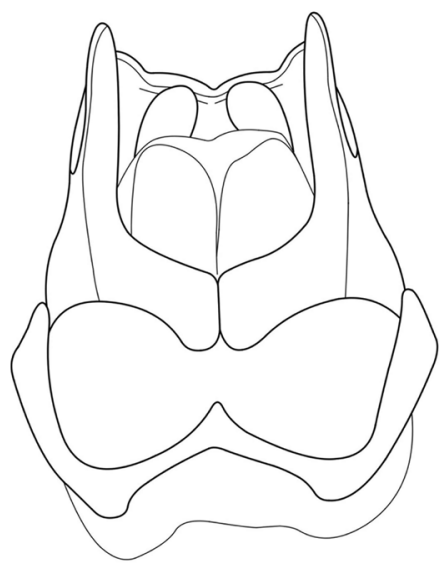

D

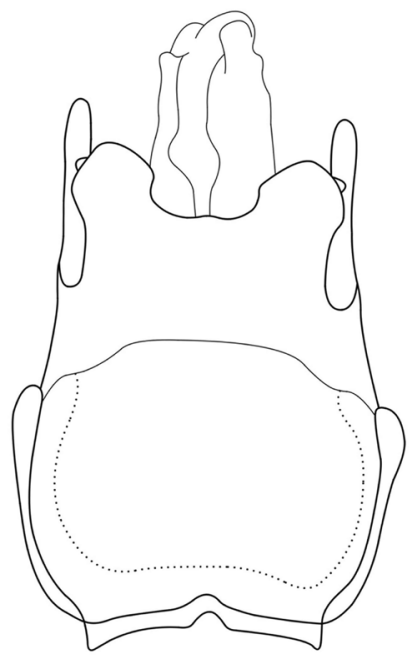

B

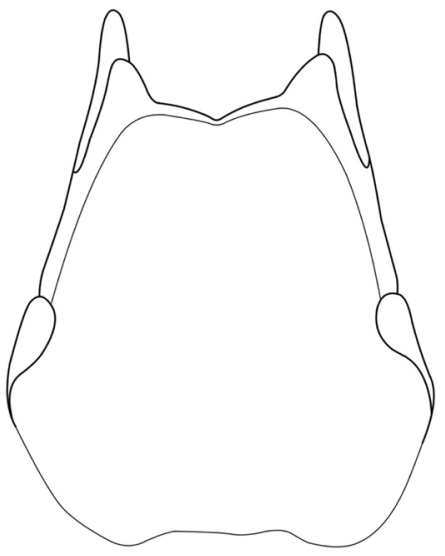

$\mathbf{E}$



C

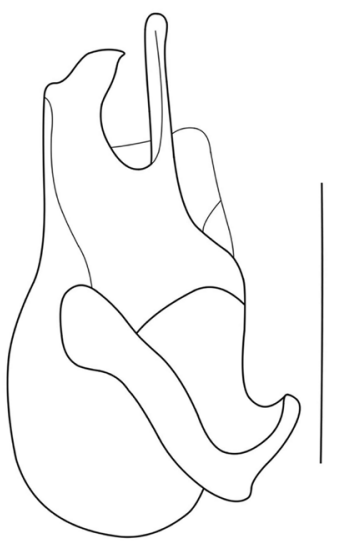

$\mathbf{F}$

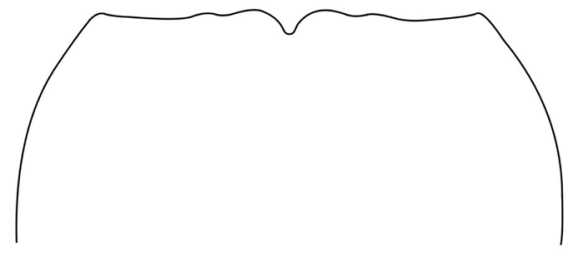

G

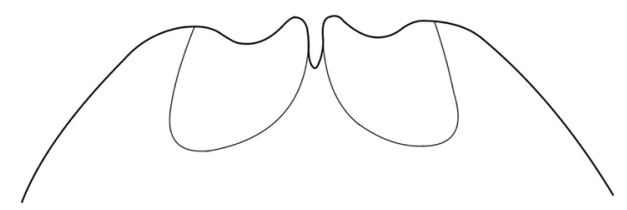

$\mathbf{H}$

Figure 2. A-F Aedeagus (A, D ventral view B, E dorsal view C, F lateral view); G-H. abdominal sternite VIII of female, ventral view: A-C, G Themus (Themus) dimorphus sp. n. D-F, H T. (T.) testaceicollis Wittmer, 1983. Scale bars $=1.0 \mathrm{~mm}$. 

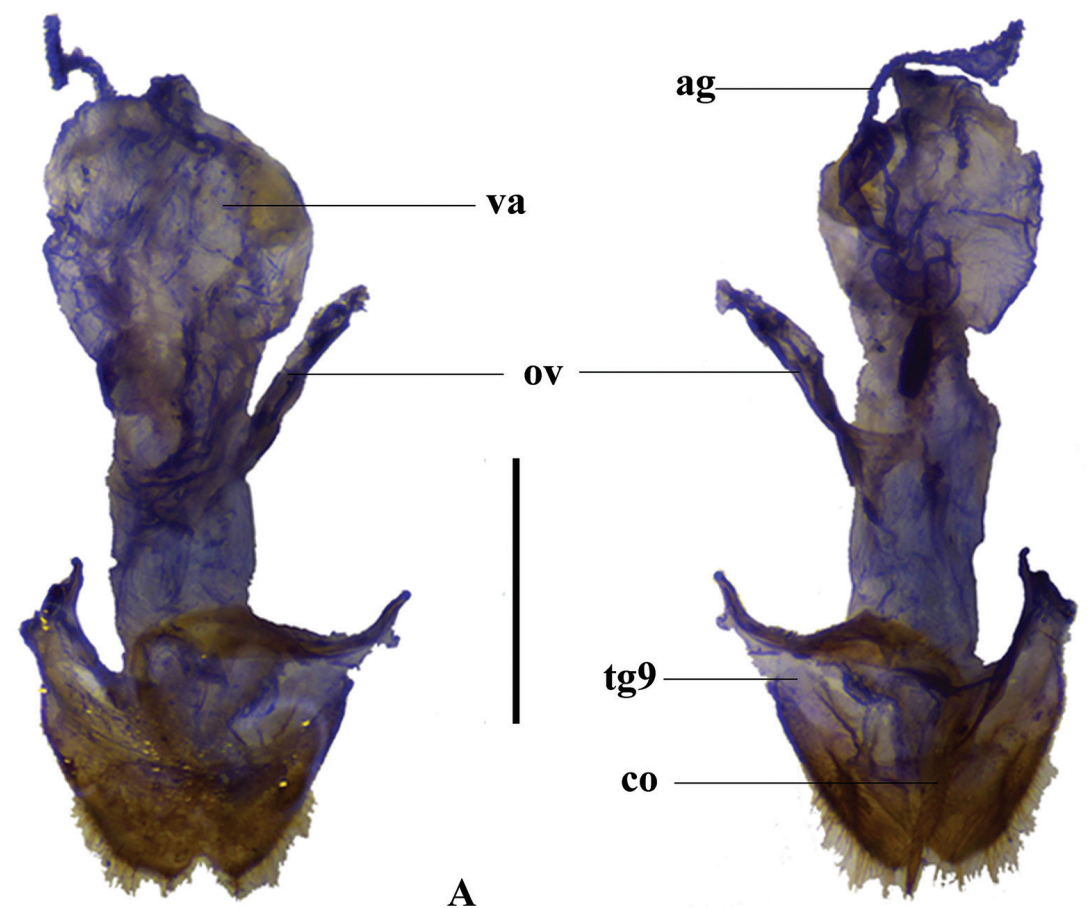

B
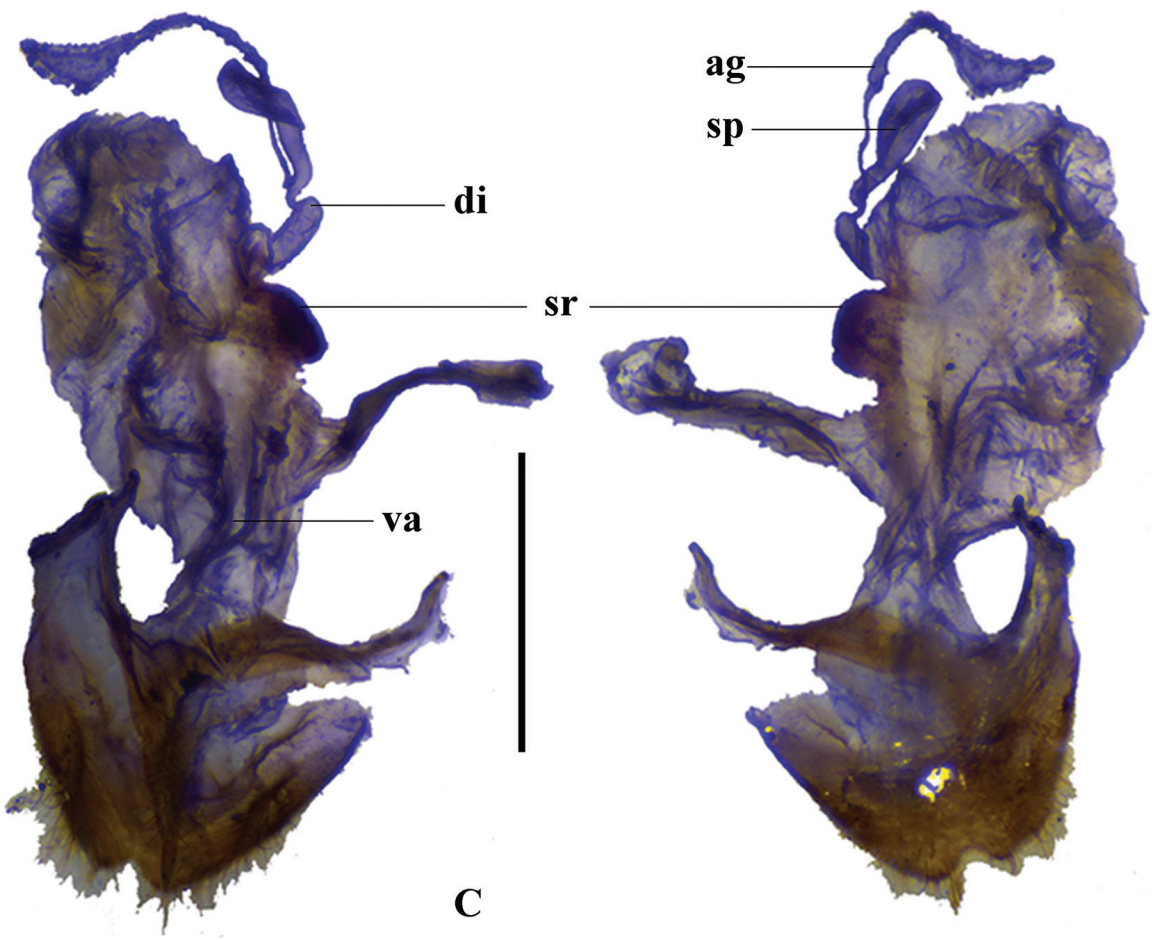

D

Figure 3. Female genitalia of Themus (Themus) dimorphus sp. n.: A dorsal view $\mathbf{B}$ ventral view $\mathbf{C}$ right lateral view D left lateral view. Scale bars $=1.0 \mathrm{~mm}$. 
approximately twice as long as wide at apices and 1.5 times as long as II, IV approximately 1.5 times as long as III, IV-XI subequal in length, each with a small round to short narrow longitudinal impression in middle or basal part of outer margin, XI pointed at apices.

Pronotum approximately 1.40 times as wide as long, widest near base, anterior margin arcuate, lateral margins slightly sinuate at anterior part and distinctly diverging posteriorly, posterior margin bisinuate and narrowly bordered, anterior angles rounded, posterior angles nearly rectangular, disc slightly convex at posterolateral parts, surface lustrous, slightly finely and sparsely punctate than that on head.

Elytra approximately 3.0 times longer than pronotum, 2.6 times longer than humeral width, lateral margins distinctly converging posteriorly, apex of each elytron rounded, disc rugulose-lacunose and coarsely punctate, surface matt.

Aedeagus (Fig. 2A-C): ventral process of each paramere narrow and straight, rounded at apex; conjoint dorsal plate of parameres slightly shorter than ventral processes, largely subroundly emarginated in middle of apical margin, with lateroapical angles acute and bent ventrally; laterophyses widely separated on both sides of median lobe, with apices acute and pointed dorsally to lateroapical angles of conjoint dorsal plate.

Female (Fig. 1B). Similar to male, but clypeus uniformly yellow; antennae narrower and shorter, extending to basal one-fifth length of elytra; antennomeres III nearly as long as II, IV-XI without impressions, XI slightly longer than X; pronotum without any black marking (one specimens with two indistinct small dark brown markings on both sides of disc); elytra approximately 2.5 times longer than humeral width, with lateral margins slightly converging posteriorly; scutellum sometimes yellow (one specimen). Abdominal sternite VIII (Fig. 2G) moderately triangularly emarginated in middle and indistinctly emarginated on both sides of posterior margin. Internal reproductive organ of genitalia (Fig. 3): vagina stout, abruptly narrowed into a short tube at apical part of ventral side, below which present with a pair of strongly sclerotized, arcuate and conjoint ridges extending to median oviduct; diverticulum and spermatheca arising from the end of the short tube of vagina; diverticulum very short and rounded at apex; spermatheca sac-shaped and rounded at apex, distinctly expanded apicad and bent in middle, provided with a moderately long and thin accessory gland at base.

Body length: $8.0-11.0 \mathrm{~mm}$; width: $3.0-4.5 \mathrm{~mm}$.

Distribution. China (Yunnan).

Etymology. The specific name is derived from Latin dimorphus (dimorphic), referring to its different coloration of head and pronotum in both sexes.

Diagnosis. The new species can be distinguished from most of the species of Themus (Themus) Motschulsky by the smaller body and uniformly orange pronotum or at most with one or two small black markings, which characters also equipped by the following species in the key.

\section{A key to Themus (Themus) dimorphus sp. $\mathrm{n}$. and its similar species}


2 Pronotum distinctly wider than long, with lateral margins nearly parallel; aedeagus: laterophyses flattened and tapered apically, slightly longer than conjoint parameres of parameres...............T. (T.) tumlonganus (Pic, 1916)

- $\quad$ Pronotum slightly wider than long, with lateral margins slightly converging posteriorly; aedeagus: laterophyses unlike above, stout, slightly shorter than conjoint dorsal plate of parameres.......T. (T.) foveicollis (Fairmaire, 1900)

3 Pronotum distinctly wider than long, with lateral margins slightly diverging posteriorly; aedeagus: conjoint dorsal plate of parameres subroundly emarginated in middle of apical margin. $T$. (T.) dimorphus sp. $\mathrm{n}$. - $\quad$ Pronotum slightly wider than long, with lateral margins slightly converging posteriorly; aedeagus: conjoint dorsal plate of parameres inverse-trapeziformly emarginated in middle of apical margin....T. (T.) testaceicollis Wittmer, 1983

\section{Themus (Themus) testaceicollis Wittmer, 1983}

Figs 1C-D, 2D-F, H, 4

Themus (s. str.?) testaceicollis Wittmer, 1983: 218, Fig. 97.

Themus (s. str.) testaceicollis: Wittmer 1995: 127.

Type material examined. Holotype: 1 female (MNHN): [h] "Tatsien Lu \1896" [CHINA, Sichuan, Kangding], [h] "Themus (s. str.?) \testaceicollis \Wittm. \det. W. Wittmer", [p] "HOLOTYPUS". Paratype: 1 female (NHMB): [p] "Ta-tsien-Loû $\backslash$ Chasseurs Thibétaíns \1896" [CHINA, Sichuan, Kangding], [h] "Themus (s.str.?) \ testaceicollis \Wittm. \det. W. Wittmer", [p] "PARATYPUS".

Additional material examined. CHINA: Shaanxi: 12 males, 7 females (IZAS): Taibai, Baiyuanxiang, Primary Forest, $33.814^{\circ} \mathrm{N}, 107.618^{\circ} \mathrm{E}, 1619 \mathrm{~m}, 19 . \mathrm{VI} .2012$, leg. Sha Li; 4 males (IZAS): Liuba, Shangtaizi, Zibaishan, 22.VI.2012, leg. Yi Hua; 1 female (MHUB): Fengxian, Heigou, 13.VI.2005, leg. Yi-Bin Ba; Hubei: 1 female (MHUB): Badong, Lvcongpo, 1700 m, 16.VII.2006, leg. Li Cai; Sichuan: 1 female (MHUB): Jiuzhaigou, Xinyangerlin, 14.VII.2009, leg. Zhen-Hua Gao \& Yi-Ping Niu.

Redescription. Male (Fig. 1C). Head metallic green and strongly shining, mouthparts metallic green, mandibles light yellow at bases and dark brown at apices, terminal maxillary and labial palpomeres dark brown, antennae black, antennomeres I-II metallic green on dorsal sides, I-VI or VIII orange on ventral sides, prothorax light yellow, pronoum orange in center of disc, scutellum, elytra and legs metallic green and strongly shinning, meso- and metasterna and abdomen metallic dark blue and strongly shining. Head and elytra densely covered with decumbent light brown pubescence, pronotum with black pubescence, meso- and metasterna and abdomen with gray pubescence, sparsely mixed with long erect pubescence along anterior margin of clypeus.

Head rounded, densely and finely punctate, surface lustrous; eyes slightly protruding, breadth across eyes slightly narrower than anterior margin of pronotum; terminal maxillary palpomeres widest nearly in middle, arcuate and sharp at apical half parts of 
inner margins, rounded at apices; antennae almost extending to mid-length of elytra, antennomeres II approximately twice as long as wide at apices, III-X slightly obliquely widened apicad, III about 1.5 times as long as wide at apices and slightly longer than II, IV approximately 1.5 times longer than III, IV-VIII subequal in length and slightly longer than the following antennomeres, IV-XI each with a short longitudinal impression nearly in middle of outer margin, XI slightly longer than X and pointed at apices.

Pronotum approximately 1.20 times as wide as long, widest before middle, anterior margin arcuate, lateral margins slightly sinuate and converging posteriorly, posterior margin bisinuate and narrowly bordered, anterior angles nearly rectangular, posterior angles rounded, disc slightly convex at posterolateral parts, finely and sparsely punctate, surface lustrous.

Elytra approximately 3.5 times longer than pronotum, 2.7 times longer than humeral width, lateral margins distinctly converging posteriorly, apex of each elytron rounded, disc rugulose-lacunose and coarsely punctate, surface matt.

Aedeagus (Fig. 2D-F): ventral process of each paramere narrow and nearly straight, rounded at apex; conjoint dorsal plate of parameres distinctly shorter than ventral processes, largely inverse-trapeziformly emarginated in middle of apical margin, present with two narrow transverse ridges near bottom of middle emargination on inner surface, lateroapical angles acute and bent ventrally in lateral view; laterophyses separated on dorsal side of median lobe, slightly shorter than conjoint dorsal plate, acute at apices which pointed towards the lower transverse ridge of conjoint dorsal plate.

Female (Fig. 1D). Similar to male, but eyes less protruding; antennae narrower and shorter, extending to basal one-fourth length of elytra; pronotum approximately 1.25 times as wide as long; elytra with lateral margins nearly parallel. Abdominal sternite VIII (Fig. 2H) each side of with a large and nearly triangular concave on posterior part, narrowly and moderately emarginated in middle and widely roundly emarginated on both sides of posterior margin, the portions between middle and lateral emarginations narrowly rounded at apices. Internal reproductive organ of genitalia (Fig. 4): vagina stout, with diverticulum and spermatheca situated at apex and median oviduct in middle of ventral side; spermatheca sac-shaped and rounded at apex, distinctly expanded apicad and bent in middle, provided with a long and thin accessory gland at base; diverticulum nearly gourd-shaped, global at apical part, with apex bent dorsally; spermatheca and diverticulum surrounded with a strongly sclerotized bracket at base, which is confluent in middle and extending to median oviduct on ventral side, the opening of spermatheca arising from left end of the sclerotized bracket on dorsal side.

Body length: 11.5-15.0 mm; width: 3.0-4.0 mm.

Distribution. China (Hubei, Sichuan, Shaanxi, Gansu).

Remarks. In the original publication (Wittmer 1983), this species was described based on female types collected in Sichuan, China. Later some male characters were supplemented (Wittmer 1995). In the present study, it is redescribed and provided with illustrations of genitalia of both sexes for the first time. And it is newly recorded in Hubei province of China. 


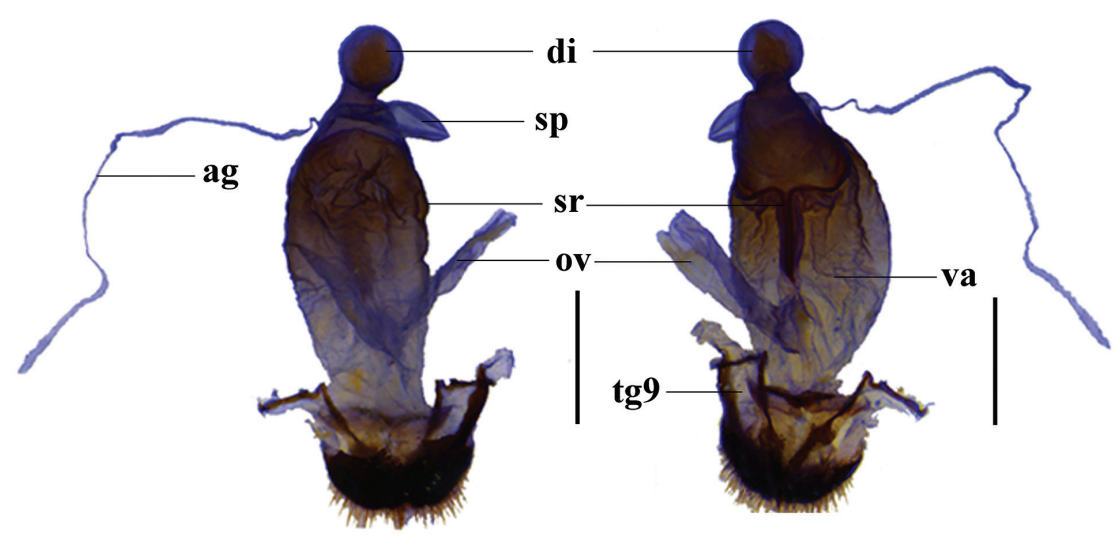

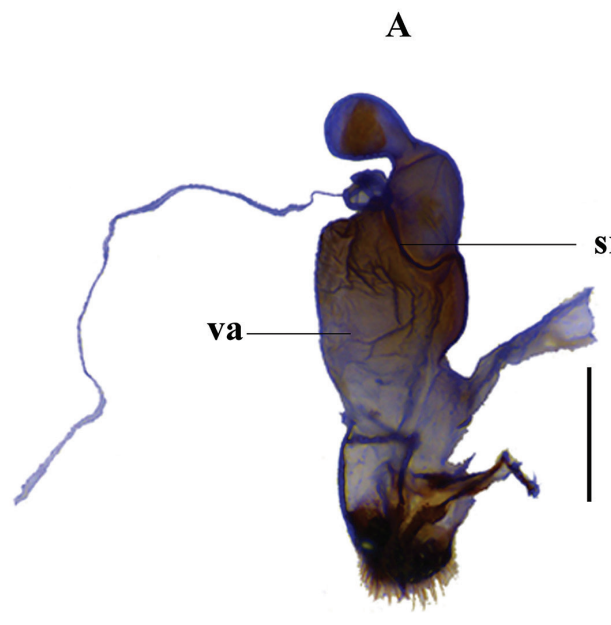

C

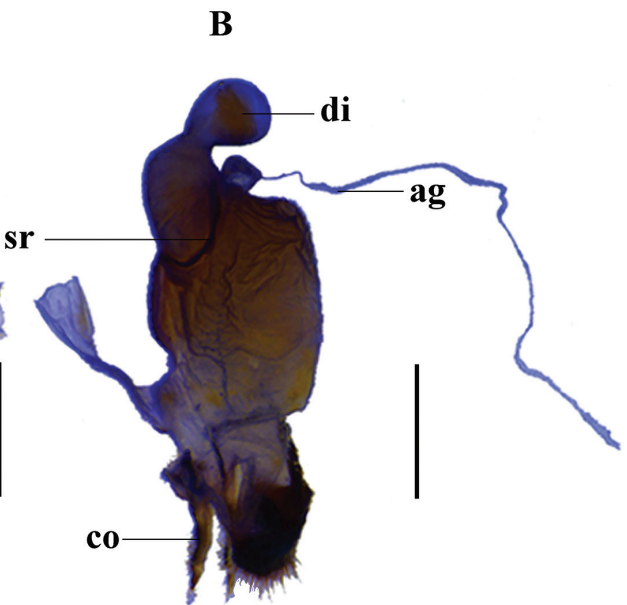

D

Figure 4. Female genitalia of Themus (Themus) testaceicollis Wittmer, 1983: A dorsal view B ventral view C right lateral view $\mathbf{D}$ left lateral view. Scale bars $=1.0 \mathrm{~mm}$.

\section{Acknowledgment}

We would like to express our deep gratitude to late Dr. Michel Brancucci (NHMB) for his kind support in loaning materials and entomological guidance for Yuxia Yang during her stay in Basel from 2008 to 2009. Also, we are grateful to Mr. Andreas Kopetz (Germany) for his comments on our original manuscript and to Mr. Antoine Mantilleri (MNHN) for providing a chance to access to the collection under his charge. Thanks are due to Mr. John MacDermott (USA) for correcting our English.

The present study was supported by the National Natural Science Foundation of China (Nos. 31172135, 41401064), the Knowledge Innovation of Chinese Academy of Sciences (No. KSCX2-EW-Z-8) and the Foundation of the Key Laboratory of Zoological Systematics and Application of Hebei Province (No. 14967611D). 


\section{References}

Brancucci M (1980) Morphologie comparée, évolution et systématique des Cantharidae (Insecta: Coleoptera). Entomologica Basiliensia 5: 215-388.

de Motschulsky V (1858) Entomologie spéciale. Insectes du Japon. Études Entomologiques 6(1857): 25-41.

Švihla V (2008) Redescription of the subgenera of the genus Themus Motschulsky, 1858, with description of five new species (Coleoptera: Cantharidae). Veröffentlichungen des Naturkundemuseums Erfurt 27: 183-190.

Wittmer W (1973) Zur Kenntnis der Gattung Themus Motsch. (Col. Cantharidae). Entomologischen Arbeiten aus dem Museum G. Frey 24: 186-228.

Wittmer W (1983) Beitrag zur einer Revision der Gattung Themus Motsch. Coleoptera: Cantharidae. Entomologischen Arbeiten aus dem Museum G. Frey 31/32: 189-239.

Wittmer W (1995) Neue Cantharidae (Col.) aus dem indo-malaiischen und palaearktischen Faunengebiet mit Mutationen. Entomologica Basiliensia 18: 109-169.

Wittmer W (1997) Neue Cantharidae (Col.) aus dem indo-malaiischen und palaearktischen Faunengebiet mit Mutationen. 2. Beitrag. Entomologica Basiliensia 20: 223-366.

Yang YX, Su JY, Kopetz A (2014) Description of three new cantharid species related to Themus (Themus) senensis (Pic, 1922) (Coleoptera, Cantharidae). Annales Zoologici 64(4): 655-666. doi: 10.3161/000345414X685938 